\begin{tabular}{|c|c|c|}
\hline leapy & $\begin{array}{l}\text { Kappa Journal } \\
\text { Program Studi Pendidikan Fisika } \\
\text { FMIPA Universitas Hamzanwadi } \\
\text { http://e-journal.hamzanwadi.ac.id/index.php/kpj/index }\end{array}$ & $\begin{array}{c}\text { Desember 2019. Vol. 3, No. } 2 \\
\text { e-ISSN: } 2549-2950 \\
\text { pp. } 71-78\end{array}$ \\
\hline
\end{tabular}

\title{
Penentuan Persamaan Empiris Percepatan Tanah Di Wilayah Bali Berdasarkan Data Gempabumi Periode 2008-2016
}

\author{
${ }^{1}$ I Putu Arix Putra Wiguna, ${ }^{2}$ I Made Yuliara \\ ${ }^{1,2}$ Program Studi Fisika, Fakultas Matematika dan Ilmu Pengetahuan Alam, Universitas \\ Udayana,Kampus Bukit Jimbaran, Badung, Bali, Indonesia 80361 \\ Email: arixputra88@gmail.com; yuliara@unud.ac.id
}

\begin{tabular}{|c|c|}
\hline Info & \multirow{3}{*}{$\begin{array}{l}\text { Abstract } \\
\text { The earthquake was the most common natural disaster in Indonesia, one of } \\
\text { which was the Province of Bali. The southern part of Bali is a meeting area of } \\
\text { two earth plates (subduction zones) between the Eurasian and Indo-Australian } \\
\text { plates and in the northern region there is a back arc thrust fracture which } \\
\text { results in earthquake frequencies in the Bali area. One of the parameters that is } \\
\text { very instrumental in determining the level of damage to land and buildings that } \\
\text { occur on the surface of the earth due to earthquake shocks is the acceleration } \\
\text { of the soil. A research has been conducted which aims to find out the empirical } \\
\text { equation of land acceleration for Bali in the } 2008-2016 \text { period, namely by } \\
\text { determining the empirical equation of land acceleration }(P G A) \text { conducted } \\
\text { using magnitude parameters, hypocenter distance and PGA (observation) } \\
\text { values in } 2008-2016 \text { with coordinates } 7^{0}-12^{0} \text { LS and } 113^{0}-118^{0} B T \text {. Through the } \\
\text { regression analysis approach, to obtain the empirical equation of land } \\
\text { acceleration in the Bali region is log } 10(P G A)=(-1,89) \text { log } 10(R)+ \\
\text { (0,71) mb }+1,18 \text {. Then several approaches and correlation analysis are } \\
\text { performed to see the compatibility of the new empirical equation with the } \\
\text { existing one. }\end{array}$} \\
\hline $\begin{array}{l}\text { Article History } \\
\text { Received:August } \\
\text { Revised: November } \\
\text { Published: Desember }\end{array}$ & \\
\hline & \\
\hline Info & Abstrak \\
\hline $\begin{array}{l}\text { Seja } \\
\text { Dite } \\
\text { Dire } \\
\text { Dipu }\end{array}$ & \multirow{2}{*}{$\begin{array}{l}\text { Gempabumi merupakan bencana alam yang paling sering terjadi di Indonesia } \\
\text { salah satunya adalah Provinsi Bali. Bagian selatan Bali merupakan daerah } \\
\text { pertemuan dua lempeng bumi (zona subduksi) antara lempeng Eurasia dan } \\
\text { Indo-Australia serta di wilayah sebelah utara terdapat patahan naik busur } \\
\text { belakang (back arc thrust) yang mengakibatkan frekuensi gempabumi di daerah } \\
\text { Bali. Salah satu parameter yang sangat berperan dalam menentukan tingkat } \\
\text { kerusakan tanah dan bangunan yang terjadi di permukaan bumi akibat } \\
\text { guncangan gempabumi adalah percepatan tanah. Telah dilakukan penelitian } \\
\text { yang bertujuan untuk mengetahui persamaan empiris percepatan tanah untuk } \\
\text { wilayah Bali periode 2008-2016, yaitu dengan cara untuk menentukan } \\
\text { persamaan empiris percepatan tanah (PGA) yang dilakukan dengan } \\
\text { menggunakan parameter magnitudo, jarak hiposenter dan nilai PGA (observasi) } \\
\text { tahun 2008-2016 dengan koordinat } 7^{0}-12^{0} \mathrm{LS} \text { dan } 113^{0}-118^{0} \text { BT. Melalui } \\
\text { pendekatan anaisis regresi, sehingga diperoleh persamaan empiris percepatan } \\
\text { tanah di wilayah Bali adalah log } 10(P G A)=(-1,89) \text { log }{ }_{10}(R)+ \\
(0,71) \text { mb }+1,18 \text {. Kemudian dilakukan beberapa pendekatan dan analisis } \\
\text { korelasi untuk melihat kecocokan persamaan empiris yang baru dengan yang } \\
\text { sudah ada sebelumnya. }\end{array}$} \\
\hline & \\
\hline
\end{tabular}

Sitasi: Wiguna. I.P.A.P., \& Yuliara, I.M. (2019). Penentuan Persamaan Empiris Percepatan Tanah Di Wilayah Bali Berdasarkan Data Gempabumi Periode 2008-2016. Kappa Journal, Pendidikan Fisika, FMIPA, Universitas Hamzanwadi. 3 (2), 71-78 


\section{PENDAHULUAN}

Percepatan tanah maksimum merupakan salah satu parameter paling peting yang digunakan untuk meninjau kerusakan tanah yang terjadi di permukaan bumi akibat dari gempabumi. Dengan mengetahui nilai dari percepatan tanah disuatu daerah, maka akan dapat diketahui wilayah yang rawan kerusakan akibat dari gempabumi. Besar nilai perepatan tanah dapat diukur dengan menggunakan sensor accelerograph.

Stasiun Geofisika Sanglah Denpasar memiliki perlengkapan jaringan seismograph dan accelerograph yang telah terintegrasi dengan baik sejak tahun 2008 dan merupakan salah faktor penting dalam penentuan nilai percepatan getaran tanah maksimum atau Peak Ground Acceleration (PGA) untuk daerah Bali, namun ketersediaan jaringan accelerograph yang terbatas dan kekhawatiran akan dampak gempabumi besar yang merusak (Priyanto, D. K.,2016), maka perlu dikembangkan persamaan empiris percepatan getaran tanah maksimum untuk daerah Bali dan sekaligus mengetahui wilayah yang beresiko mengalami kerusakan tertinggi akibat dari gempabumi.

Banyak studi kasus yang telah dilakukan untuk menentukan persamaan empiris percepatan tanah disuatu daerah. Diantaranya: Yohanes (Bali), Lin dan Wu (Taiwan), McVerry (New Zealand), Fukushima dan Tanaka (Jepang). Adapun tujuan dari penelitian ini adalah untuk mencari persamaan empiris percepatan tanah baru yang sesuai dengan data observasi dari accelerograph tahun 2008-2016.

\section{METODE}

Pada beberapa penelitian sebelumnya, perumusan rumus empiris hanya bergantung pada nilai magnitudo, jarak hiposenter dan kedalaman. Salah satu peneliti yang menggunakan parameter-parameter tersebut adalah Lin dan $\mathrm{Wu}$ (2010). Lin dan $\mathrm{Wu}$ membuat persamaan empiris percepatan tanah di daerah Taiwan, persamaan empiris ini merupakan pengembangan dari persamaan umum percepatan tanah:

$$
\log _{10}(P G A)=a \log _{10}(R)+b M+c
$$

dengan:

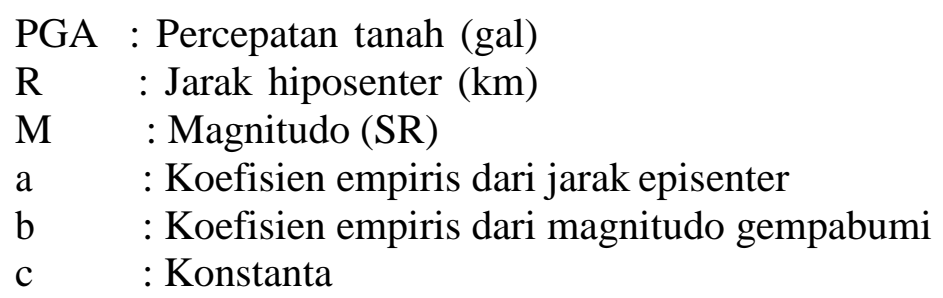

Nilai R merupakan jarak hiposenter (hiposentrum) yang merupakan jarak dari accelerometer ke pusat gempabumi dengan memperhitungkan kedalaman dari gempabumi atau pusat gempabumi, sedangkan jarak episenter merupakan jarak dari accelerometer ke pusat gempabumi tanpa memperhitungkan kedalaman dari gempabumi atau pusat gempabumi. Nilai R atau jarak hiposenter dapat dihitung dengan menggunakan rumus segitigabola:

$$
S=\sqrt{(L s t a-L e p i)^{2}+(B s t a-B e p i)^{2}} \times 111 \mathrm{~km}
$$

dengan:

$$
\begin{array}{ll}
S & =\text { jarak stasiun ke episenter }(\mathrm{km}) \\
L \text { sta } & =\text { lintang stasiun } \\
\text { L epi } & =\text { lintang episenter } \\
\text { B sta } & =\text { bujur stasiun }
\end{array}
$$




$$
B \text { epi = bujur hiposenter }
$$

Sehingga didapatkan persamaan untuk jarak hiposenter adalah:

dengan:

$$
R^{2}=S^{2}+h^{2}
$$

$R=$ jarak hiposenter $(\mathrm{km})$

$h=$ kedalaman $(\mathrm{km})$

Untuk mendapatkan nilai a, b dan c pada persamaan (1) maka diperlukan analisis regresi. Secara umum regresi linier ada dua, yaitu regresi linier sederhana yaitu dengan satu variabel bebas dan satu variabel terikat, serta regresi linier berganda dengan beberapa variabel bebas dan satu variabel terikat. Analisis regresi linier digunakan untuk melihat pengaruh variabel bebas terhadap variabel terikat dan memprediksi nilai variabel terikat dengan menggunakan variabel bebas. Persamaan umum analisis regresi linier berganda adalah:

$$
Y=a+b_{1} X_{1}+b_{2} X_{2}+\ldots+b_{n} X_{n}
$$

Korelasi sederhana digunakan untuk mengetahui hubungan di antara dua variabel. Hubungan antara satu variabel dengan variabel yang lain biasa disebut dengan koefisien korelasi yang ditandai dengan " $r$ " dengan persamaan berikut.

$$
r=\frac{n \sum x y-\left(\sum x\right)\left(\sum y\right)}{\sqrt{\left(n \sum x^{2}-\left(\sum x\right)^{2}\right)\left(n \sum y^{2}-\left(\sum y\right)^{2}\right)}}
$$

dan menghitung nilai erornya dengan persamaan:

$$
\operatorname{RMS} \text { Error }=\sum_{i=1}^{n} \stackrel{e_{i}^{2}}{n}
$$

dengan:

$$
\mathrm{e}_{\mathrm{i}}=\log P G A \text { (observasi) }-\log P G A \text { (empiris) }
$$

Untuk memudahkan melakukan interpretasi mengenai kekuatan hubungan antara dua variabel maka dibuat tabel sebagai berikut.

Tabel 1. Tabel Interpretasi Koefisien Korelasi

\begin{tabular}{ll}
\hline $\mathrm{r}$ & INTERPRETASI \\
\hline 0 & Tidak Ada Korelasi \\
$>0-0,25$ & Korelasi Sangat Lemah \\
$>0,25-0,5$ & Korelasi Cukup \\
$>0,5-0,75$ & Korelasi Kuat \\
$>0,75-0,99$ & Korelasi Sangat Kuat \\
1 & Korelasi Sempurna \\
\hline
\end{tabular}

\section{HASIL DAN PEMBAHASAN}

\section{Data hasil pengukuran dan perhitungan}

Data yang diperoleh dari hasil pengukuran dan perhitungan untuk menentukan persamaan empiris percepatan tanah di wilayah Bali tahun 2008-2016, yaitu berupa data $P G A$ (observasi), jarak hiposenter dan magnitudo gempabumi yang ditunjukan pada Tabel 2. 
Tabel 2. Data Hasil Pengukuran dan Perhitungan $P G A$ (observasi)

\begin{tabular}{|c|c|c|c|c|c|}
\hline No & $\begin{array}{l}\text { PGA (observasi) } \\
\text { (gal) }\end{array}$ & $\begin{array}{c}\mathrm{R} \\
(\mathrm{km})\end{array}$ & $\mathrm{mb}(\mathrm{SR})$ & $\begin{array}{c}\log \text { PGA (observasi) } \\
\text { (gal) }\end{array}$ & $\log \mathrm{R}(\mathrm{km})$ \\
\hline 1 & 4,48 & 281 & 5,73 & 0,651278014 & 2,44870632 \\
\hline 2 & 0,32 & 341 & 5,73 & $-0,494850022$ & 2,532754379 \\
\hline 3 & 1,35 & 274 & 5,73 & 0,130333768 & 2,437750563 \\
\hline 4 & 0,21 & 296 & 5 & $-0,677780705$ & 2,471291711 \\
\hline 5 & 0,05 & 357 & 5 & $-1,301029996$ & 2,552668216 \\
\hline 6 & 0,12 & 290 & 5 & $-0,920818754$ & 2,462397998 \\
\hline 7 & 1,56 & 247 & 5,26 & 0,193124598 & 2,392696953 \\
\hline 8 & 1,43 & 226 & 5,26 & 0,155336037 & 2,354108439 \\
\hline 9 & 5,55 & 289 & 4,91 & 0,744292983 & 2,460897843 \\
\hline 10 & 0,27 & 358 & 4,91 & $-0,568636236$ & 2,553883027 \\
\hline 11 & 70,52 & 66 & 5,49 & 1,848312304 & 1,819543936 \\
\hline 12 & 5,81 & 253 & 4,67 & 0,764176132 & 2,403120521 \\
\hline 13 & 0,20 & 269 & 4,67 & $-0,698970004$ & 2,42975228 \\
\hline 14 & 4,64 & 257 & 4,79 & 0,666517981 & 2,409933123 \\
\hline 15 & 0,16 & 273 & 4,79 & $-0,795880017$ & 2,436162647 \\
\hline 16 & 4,18 & 296 & 5,02 & 0,621176282 & 2,471291711 \\
\hline 17 & 0,39 & 353 & 5,02 & $-0,408935393$ & 2,547774705 \\
\hline 18 & 7,70 & 214 & 4,91 & 0,886490725 & 2,330413773 \\
\hline 19 & 43,54 & 113 & 5,96 & 1,638888425 & 2,053078443 \\
\hline 20 & 8,39 & 161 & 5,96 & 0,923761961 & 2,206825876 \\
\hline 21 & 21,55 & 118 & 5 & 1,333447274 & 2,071882007 \\
\hline 22 & 8,18 & 122 & 5 & 0,912753304 & 2,086359831 \\
\hline 23 & 1,01 & 171 & 5 & 0,004321374 & 2,23299611 \\
\hline 24 & 1,63 & 208 & 4,8 & 0,212187604 & 2,318063335 \\
\hline 25 & 0,78 & 316 & 4,7 & $-0,107905397$ & 2,499687083 \\
\hline 26 & 19,28 & 267 & 5,96 & 1,28510703 & 2,426511261 \\
\hline 27 & 2,08 & 277 & 5 & 0,318063335 & 2,442479769 \\
\hline 28 & 1,87 & 279 & 5,2 & 0,271841607 & 2,445604203 \\
\hline 29 & 1,15 & 271 & 4,9 & 0,06069784 & 2,432969291 \\
\hline 30 & 3,43 & 275 & 5,4 & 0,53529412 & 2,439332694 \\
\hline 31 & 1,33 & 273 & 5,3 & 0,123851641 & 2,436162647 \\
\hline 32 & 6,12 & 272 & 5,49 & 0,786751422 & 2,434568904 \\
\hline 33 & 1,42 & 273 & 5,3 & 0,152288344 & 2,436162647 \\
\hline 34 & 1,04 & 272 & 4,9 & 0,017033339 & 2,434568904 \\
\hline 35 & 26,76 & 84 & 5 & 1,427486109 & 1,924279286 \\
\hline 36 & 0,81 & 122 & 5 & $-0,091514981$ & 2,086359831 \\
\hline 37 & 2,57 & 299 & 4,8 & 0,409933123 & 2,475671188 \\
\hline 38 & 2,01 & 131 & 4,6 & 0,303196057 & 2,117271296 \\
\hline 39 & 0,89 & 382 & 4,6 & $-0,050609993$ & 2,582063363 \\
\hline 40 & 4,29 & 269 & 4,5 & 0,632457292 & 2,42975228 \\
\hline 41 & 16,30 & 113 & 5,1 & 1,212187604 & 2,053078443 \\
\hline 42 & 16,83 & 251 & 5,61 & 1,226084116 & 2,399673721 \\
\hline 43 & 1,10 & 221 & 5 & 0,041392685 & 2,344392274 \\
\hline
\end{tabular}




\begin{tabular}{|c|c|c|c|c|c|}
\hline 44 & 0,24 & 288 & 5,1 & $-0,619788758$ & 2,459392488 \\
\hline 45 & 9,83 & 161 & 5,2 & 0,992553518 & 2,206825876 \\
\hline 46 & 2,21 & 250 & 5,3 & 0,344392274 & 2,397940009 \\
\hline 47 & 7,19 & 158 & 5 & 0,85672889 & 2,198657087 \\
\hline 48 & 0,58 & 355 & 4,6 & $-0,236572006$ & 2,550228353 \\
\hline 49 & 2,44 & 92 & 4,5 & 0,387477345 & 1,963787827 \\
\hline 50 & 1,46 & 137 & 4,5 & 0,16343408 & 2,136720567 \\
\hline 51 & 1,00 & 272 & 4,8 & $-0,000658955$ & 2,434568904 \\
\hline 52 & 9,20 & 139 & 4,9 & 0,963883244 & 2,1430148 \\
\hline 53 & 1,85 & 199 & 4,6 & 0,266962252 & 2,298853076 \\
\hline 54 & 1,99 & 166 & 4,5 & 0,299903341 & 2,220108088 \\
\hline 55 & 2,44 & 96 & 4,6 & 0,387477345 & 1,982271233 \\
\hline 56 & 1,08 & 108 & 4,5 & 0,031737424 & 2,033423755 \\
\hline 57 & 1,78 & 218 & 4,6 & 0,250400332 & 2,338456494 \\
\hline 58 & 4,37 & 148 & 4,7 & 0,640481721 & 2,170261715 \\
\hline 59 & 5,44 & 167 & 5,2 & 0,735764704 & 2,222716471 \\
\hline 60 & 4,92 & 286 & 5,2 & 0,691868234 & 2,456366033 \\
\hline 61 & 5,05 & 109 & 4,5 & 0,70343523 & 2,037426498 \\
\hline 62 & 3,07 & 130 & 4,6 & 0,487574724 & 2,113943352 \\
\hline 63 & 1,59 & 233 & 4,9 & 0,200054245 & 2,367355921 \\
\hline 64 & 0,29 & 372 & 4,7 & $-0,533263949$ & 2,57054294 \\
\hline 65 & 1,57 & 173 & 4,5 & 0,195761827 & 2,238046103 \\
\hline 66 & 3,66 & 97 & 4,7 & 0,563471635 & 1,986771734 \\
\hline 67 & 3,82 & 136 & 4,7 & 0,581789263 & 2,133538908 \\
\hline 68 & 10,72 & 312 & 6 & 1,030070145 & 2,494154594 \\
\hline 69 & 1,67 & 222 & 4,7 & 0,222374547 & 2,346352974 \\
\hline 70 & 2,01 & 76 & 4,6 & 0,303509719 & 1,880813592 \\
\hline 71 & 0,86 & 312 & 4,9 & $-0,065023799$ & 2,494154594 \\
\hline 72 & 2,38 & 259 & 4,6 & 0,375865668 & 2,413299764 \\
\hline 73 & 1,42 & 165 & 4,5 & 0,152705563 & 2,217483944 \\
\hline 74 & 20,61 & 260 & 6,1 & 1,31403682 & 2,414973348 \\
\hline 75 & 2,85 & 84 & 4,5 & 0,455446211 & 1,924279286 \\
\hline
\end{tabular}

Berdasarkan data Tabel 2, maka dapat ditentukan persamaan empiris percepatan tanah. Melalui perhitungan analisis regresi, maka diperoleh koefisien $\mathrm{a}, \mathrm{b}$ dan konstanta $\mathrm{c}$ untuk persamaan empiris percepatan tanah maksimum di wilayah Bali, yaitu:

$$
\mathrm{a}=-1,89 \quad \mathrm{~b}=0,71 \quad \mathrm{c}=1,18
$$

Sehingga persamaan $P G A$ (empiris) berdasarkan data gempabumi tahun 2008-2016, adalah sebagai berikut:

$$
\log _{10}(P G A)=-1,89 \log _{10}(R)+0,71 m b+1,18
$$

\section{Pendekatan hasil log $P G A$ (observasi) dengan $\log P G A$ (empiris)}

Setelah mendapatkan rumus empiris percepatan tanah, maka selanjutnya memperlihatkan pendekatan hasil model atau hasil persamaan empiris percepatan tanah (PGA) yang diperoleh dari perhitungan dengan nilai observasi accelerograph menggunakan data tahun $2008-2016$ untuk melihat tingkat ketepatannya, seperti yang diperlihatkan pada Gambar 1. 


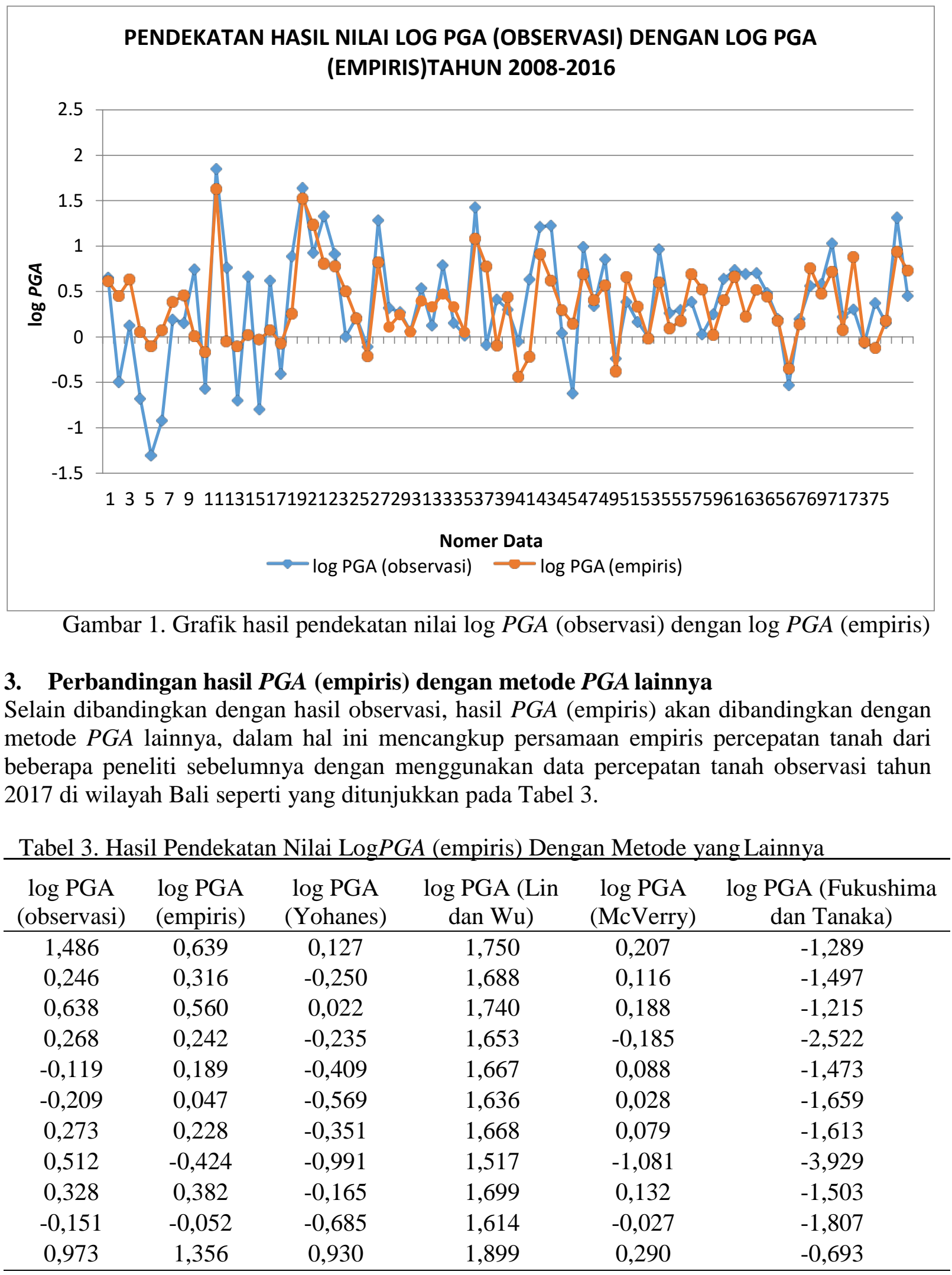




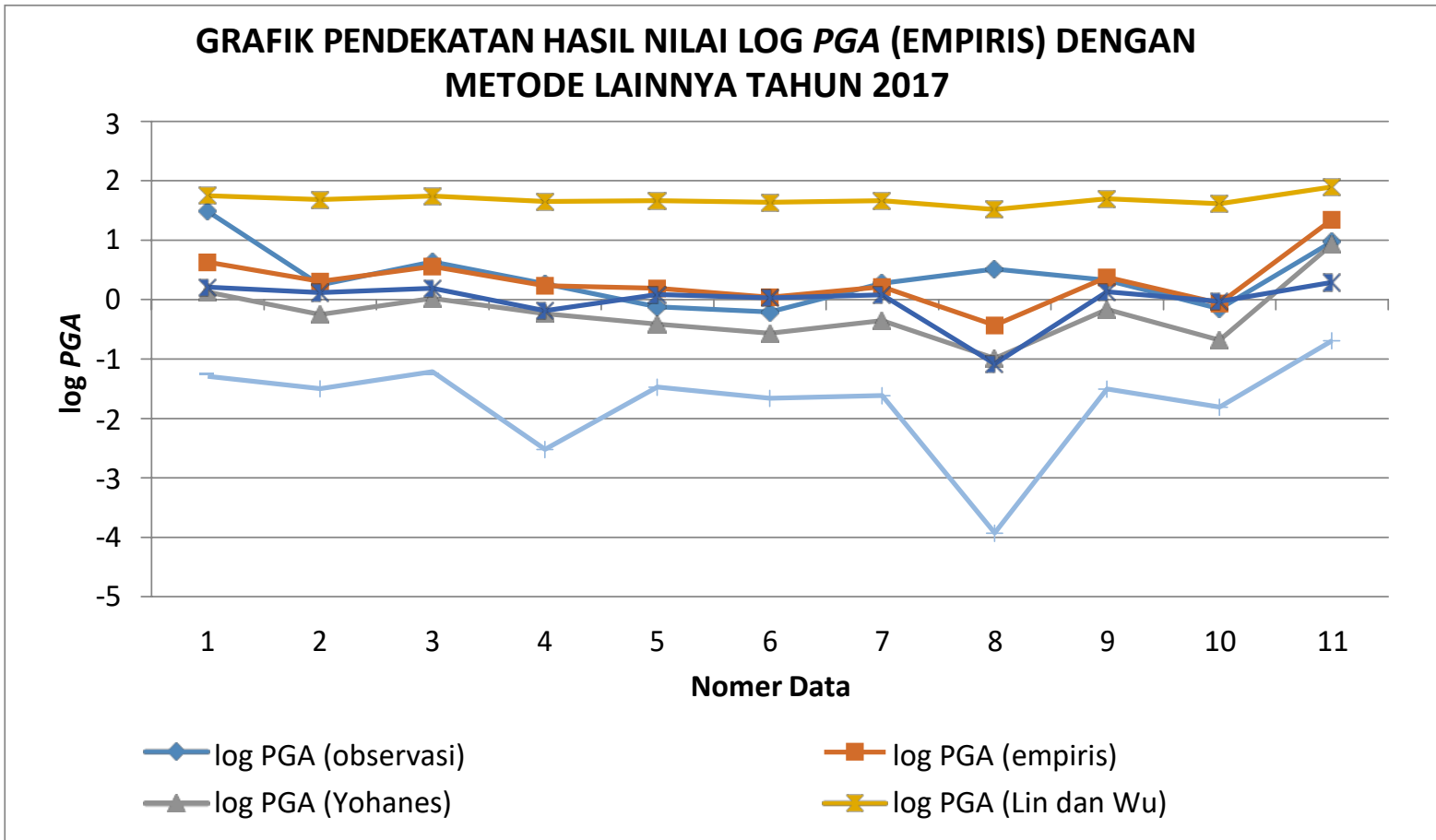

Gambar 2. Grafik hasil pendekatan nilai $\log P G A$ (empiris) dengan metode lainya tahun 2017

Pada Gambar 2 memperlihatkan bahwa hasil dari $\log P G A$ (empiris) lebih mendekati nilai observasi dibandingkan hasil metode lainnya, maka dapat dikatakan persamaan empiris percepatan tanah yang dibuat memiliki pendekatan yang cukup kuat dengan hasil observasi dari alat accelerograph jika dibandingkan metode lainnya.

Untuk melakukan verifikasi hasil $P G A$ (empiris) dengan metode percepatan tanah lainnya digunakan pendekatan yaitu Korelasi dan RMS Error, hasil yang ditunjukan pada Tabel 4.

Tabel 4. Hasil Verifikasi Tiap Persamaan Empiris Terhadap Hasil Observasi

\begin{tabular}{cccccc}
\hline $\begin{array}{c}\text { Fungsi } \\
\text { Atenuasi }\end{array}$ & Empiris & Yohanes & Lin dan Wu & Mcverry & $\begin{array}{c}\text { Fukushima Dan } \\
\text { Tanaka }\end{array}$ \\
\hline r (Korelasi) & 0,60 & 0,63 & 0,56 & 0,13 & 0,20 \\
\hline RMS Error & 0,18 & 0,55 & 1,88 & 0,47 & 5,22 \\
\hline
\end{tabular}

Dari hasil metode verifikasi pada Tabel 4, nilai koefisien korelasi (r) PGA (empiris) dapat diinterpretasikan kuat. Jika dilihat dari nilai RMS Error, $P G A$ (empiris) mempunyai nilai yang paling kecil yaitu 0,18 dibandingkan nilai RMS Error lainnya. Secara statistik, $P G A$ (empiris) menunjukkan hasil yang relatif baik dibandingkan dengan persamaan empiris lainnya.

\section{KESIMPULAN}

Berdasarkan hasil penelitian yang dilakukan maka dapat disimpulkan bahwa Persamaan empiris percepatan tanah di daerah Bali periode 2008-2016, dapat ditentukan dengan menggunakan pendekatan analisis regresi dan hasil yang diperoleh adalah:

$$
\mathrm{a}=-1,89 \quad \mathrm{~b}=0,71 \quad \mathrm{c}=1,18
$$

Sehingga diperoleh persamaan empiris percepatan tanah di wilayah Bali sebagai berikut:

$$
\log _{10}(P G A)=(-1,89) \log _{10}(R)+(0,71) m b+1,18
$$


Persamaan empiris yang didapat memiliki kecocokan yang bagus dibandingkan persamaan empiris yang sudah ada sebelumnya.

\section{SARAN}

Dengan didapatnya persamaan empiris percepatan tanah yang baru di wilayah bali, penulis menyarankan untuk dilakukannya pengembangan terhadap persamaan empiris yang didapat dengan menambah data observasi ditiap sensor, memperhitungkan periode dominan ditiaptiap sensor yang tersebar di wilayah Bali, dan memperhitungkan Vs30 sehingga dapat memperoleh persamaan empiris yang lebih akurat lagi, dan dapat dibuat daerah dengan tingkat resiko kerusakan bangunan akibat percepatan tanah maksimum.

\section{DAFTAR PUSTAKA}

Lay. T and Wallace. T. C. 1995. Modern Global Seismology. Academic Press. San Diego. 1517.

Lin and Wu. 2010. Magnitude Determination Using Strong Ground Motion Attenuation in Earthquake Early Warning. Geophysical Research Letters. Vol.37, L07304.

Nugroho H.A.. 2005. Penggunaan Data Signal Accelerograph SMR-4000 Untuk Menentukan Harga Percepatan Tanah Pada Stasiun Geofisika Sanglah Denpasar. BMKG: Bali.

Priyanto, D. K.. 2016. Penentuan Koefisien Dan Konstanta Formula Empiris Percepatan Getaran Tanah Di Daerah Denpasar. Skirpsi. Jurusan Fisika Fakultas Matematika dan Ilmu Pengetahuan Alam Universitas Udayana.

USGS. Search Earthquake Catalog diakses pada tanggal 18 Januari 2018, dari https://earthquake.usgs.gov/earthquakes/search/. 